\title{
El Lado Oscuro del reconocimiento estatal. ¿Burocratizacion del reclamo o violencia epistemica?
}

\author{
The Dark Side of state recognizance. \\ ¿bureaucratization of claims or epistemic violence?
}

Verónica Samanta Guiñazú
Facultad de Filosofía y Letras
Universidad de Buenos Aires
(Argentina)
guinazusamanta@gmail.com

Sandra Tolosa

Facultad de Filosofía y Letras Universidad de Buenos Aires

Museo Etnográfico J.B. Ambrosetti

(Argentina)

cahsandra@hotmail.com

\section{Resumen}

E1 Estado argentino ha ido redefiniendo su relación con los Pueblos Originarios a través de diversas acciones de reconocimiento de sus derechos, particularidades y reclamos, elaborando variadas políticas públicas, programas y proyectos a través de instituciones y agencias específicas que presentan esta "renovada" relación como producto de un genuino reconocimiento a la pluriculturalidad y a las identidades étnicas preexistentes al Estado. Contrariamente, observamos que las formas concretas de ejecución de estos evidencian otras lógicas subyacentes, que demuestran la profunda contradicción que existe en la concepción misma de esta relación entre el Estado y los Pueblos. Este artículo analiza cómo las formas que el Estado utiliza para el reconocimiento de la pluralidad étnica pueden transformarse en procesos determinados por la violencia epistémica e institucional. Para ello, nos centramos en los procedimientos de petición, inscripción y formalización que los Pueblos Originarios deben realizar para lograr el reconocimiento de sus Comunidades y Organizaciones. En ese sentido, nos interesa desnaturalizar estos procedimientos a fines de discutir la pretendida

GUIÑAZÚ, Verónica Samanta y TOLOSA, Sandra, "El lado oscuro del reconocimiento estatal. ¿Burocratización del reclamo o violencia epistémica?”, en Avances del Cesor, Año XI, № 11, segundo semestre de 2014, pp. 77-98. 
inocencia o neutralidad de los formularios y requisitos formales de reconocimiento estatal, para demostrar cómo éstos, en tanto herramientas, así como las instituciones que los operan, responden a una ideología subyacente que lejos de reconocer y respetar plenamente las diversidad y particularidades de los Pueblos, actúa imponiéndoles criterios, categorías y formas de la identidad que surgen de la propia lógica del Estado.

Palabras clave: Violencia epistémica - Violencia institucional - Pueblos Originarios

\begin{abstract}
The Argentinean State has been redefining his relationship with indigenous people through various actions for recognition of their rights, and specific claims; developing various public policies, programs and projects through specific institutions and agencies that have this "renewed" relationship as product of a genuine appreciation for multiculturalism and ethnic identities predate the state. In contrast, we observed that the specific forms of implementation of these other logics underlying evidence, demonstrating the profound contradiction in the conception of the relationship between the state and the indigenous people. This article analyzes the ways that the state uses to recognize the ethnic processes can become determined by epistemic and institutional violence. To do this, we focus on application, registration and formalization procedures that Indigenous People must perform to achieve recognition of their communities and organizations. In that sense, we are interested to denature the following purposes of discussing the alleged innocence or neutrality of forms and formal requirements for state recognition, to demonstrate how these, in both tools and institutions that operate them, respond to underlying ideology far from fully recognize and respect the diversity and particularities of Indigenous People acts imposing criteria, categories and forms of identity arising from the logic of the state.
\end{abstract}

Keywords: Bureaucratization - Epistemic Violence - Institutional Violence - Native People

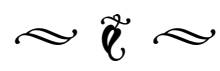

\section{Introducción}

Durante las dos últimas décadas el Estado argentino, en consonancia con cambios a nivel regional y mundial, ha ido redefiniendo su relación con los Pueblos originarios a través de diversos reconocimientos de sus derechos y particularidades, elaborando políticas públicas a través de instituciones y agencias específicas, que presentan esta "renovada" relación como producto de un genuino reconocimiento a la pluriculturalidad y a las identidades étnicas preexistentes al Estado. Sin embargo, en detrimento de estos bienintencionados objetivos, las formas concretas de ejecución utilizadas para llevarlos a cabo evidencian otras lógicas subyacentes, que indican una profunda contradicción en la concepción misma de la relación actual entre Estado y Pueblos originarios.

En este artículo proponemos un análisis preliminar sobre cómo las formas concretas que el Estado utiliza para el reconocimiento de la pluralidad étnica pueden transformarse en 
procesos determinados por la violencia epistémica e institucional ${ }^{1}$. Para ello, nos centraremos en el análisis de tres procedimientos registrales específicos del Instituto Nacional de Asuntos Indígenas (INAI), a cumplir por los Pueblos originarios para solicitar el reconocimiento estatal, sea sobre sus comunidades, organizaciones o territorios: el Registro Nacional de Comunidades Indígenas (RENACI), el Relevamiento Territorial de Comunidades Indígenas (RETECI) y el Registro Nacional de Organizaciones de Pueblos Indígenas (RENOPI). Consideramos que el conjunto de estos registros y sus procedimientos constituyen no sólo una respuesta frente a los aspectos más importantes de la lucha indígena, sino también un modo de regulación y control de la misma.

En esta línea, se hace necesario desnaturalizar estos procedimientos a fin de discutir tanto la pretendida inocencia o neutralidad de los formularios y requisitos formales, como sus

1. Presentamos el presente artículo como un análisis preliminar que forma parte de un trabajo conjunto más amplio, en el que analizamos aspectos específicos del actual panorama de la política indígena y su relación con el Estado, a partir de los dispositivos de regulación que éste último implementa. Como antropólogas en relación con diferentes comunidades indígenas -a partir de los trabajos de campo particulares de cada una, en Tucumán y Río Negro- y con activistas de organizaciones nacionales, hemos venido observando críticamente diferentes instancias de ese tenso "diálogo", que creemos que es necesario problematizar. De este modo, a partir de los planteos surgidos en distintas entrevistas en relación a las dificultades y contradicciones que aparecen a la hora de realizar los trámites de inscripción en los distintos registros del INAI con el fin de obtener derechos tales como la personería jurídica, el acceso al relevamiento territorial y el reconocimiento de las organizaciones, decidimos indagar en el corpus de esa normativa, observando los requerimientos propuestos y las implicancias concretas de las distintas tramitaciones, con el fin de analizar las lógicas que subyacen al sistema burocrático actual, ideado para dar solución a las demandas indígenas. objetivos expresos; para analizar luego cómo este conjunto de herramientas, operadas institucionalmente responden, más que al reconocimiento y respeto pleno de la diversidad y riqueza de los Pueblos, a una ideología subyacente que actúa imponiendo criterios, categorías y formas de la identidad que surgen de la propia lógica del Estado. En este proceso, identificamos dos principales formas de violencia. Por un lado, la violencia institucional ejercida en la misma imposición de los mecanismos burocráticos que, presentados como único acceso al diálogo con el Estado y sin asumir las distintas realidades sociales de los actores, homogeneízan su diversidad a través de la exigencia de respuestas formateadas de acuerdo a sus propios criterios. Por otro lado, estas imposiciones implican una profunda violencia epistémica, a través de la cual se obliga a los Pueblos a traducir sus propias formas de conceptualizarse al lenguaje burocrático, transformar aspectos de sí mismos para poder cumplir con los requerimientos formales o negar aquellos otros que no son de interés para el Estado. Consideramos que estas formas de la violencia no sólo son efectos no deseados del mecanismo procedimental, sino que constituyen la forma actual de control estatal sobre los distintos procesos de etnización y reterritorialización y por lo tanto de la autonomía política de los Pueblos, que funciona limitando su acción a través de la asimilación y homogeneización de los reclamos en un sistema discursivamente "inclusivo" que termina dilatando ad infinitum la resolución de los mismos.

Para abordar este problema comenzaremos por sintetizar algunos elementos que permitan contextualizar el surgimiento del INAI como el organismo estatal específico que se ocupa de las problemáticas indígenas. Analizaremos 
luego los tres registros mencionados, centrándonos en aquellos aspectos de la ejecución que conllevan elementos de violencia. Por último, plantearemos algunas iniciales reflexiones sobre el sentido de control y regulación de la autonomía política indígena que estos sistemas implican.

\section{Las formas del "reconocimiento" estatal}

A partir de la vuelta a la democracia en la Argentina en 1983 y principalmente en las dos últimas décadas, se han sucedido diferentes disposiciones legales, nacionales y provinciales, tendientes a materializar una "ideología del reconocimiento" de la diversidad, las demandas y los reclamos indígenas. Esta apertura estuvo condicionada por un contexto internacional que orientó los nuevos modos de gubernamentalidad y, bajo formas modernas y neoliberales, se expresó en maneras particulares de producir alteridades. ${ }^{2}$ Sin embargo, coincidiendo con Restrepo, ${ }^{3}$ entendemos que "las políticas de las

\footnotetext{
2. SIEDER, Rachel, "Del indigenismo institucional integracionista a la gestión pluralista de las políticas públicas", en Memorias del Cuarto Congreso de la Red Latinoamericana de Antropología Jurídica (RELAJU). Globalización y pluralismo jurídico: Luchas sociales y legales en la construcción de Estados interculturales, Quito, 2004. (en prensa)

BRIONES, Claudia, "Formaciones de alteridad: contextos globales, procesos nacionales y provinciales", en Claudia Briones (editora), Cartografías argentinas. Politicas indigenistas y formaciones provinciales de alteridad, Antropofagia, Buenos Aires, 2005.

CORRIGAN, Philipe y SAYER, Derek, The Great Arch. English State Formation as Cultural Revolution. Basil Blackwell, Oxford, 1985.
}

3. RESTREPO, Eduardo, "Biopolítica y alteridad: dilemas de la etnización de las colombias negras", en RESTREPO, Eduardo y ROJAS, Axel, Conflicto e (in) visibilidad Retos en los estudios de la gente negra en Colom- diferencias" se conectan de maneras múltiples con las articulaciones de alteridad que las han antecedido y, en este sentido, que las matrices de alteridad coloniales continúan actualizándose en el presente -en menor o diferente medida- mediante las prácticas de marcación de ciertos colectivos como aquellos "otros internos", ${ }^{4}$ que son incorporados a la nación. En nuestro país, los parámetros de los organismos internacionales permitieron algunos acuerdos generalizados sobre los que producir políticas, orientando las marcaciones de "otredad" según esos criterios.

A modo enumerativo, las principales disposiciones a nivel nacional de este último período son la Ley No 23.302 de 1985 sobre Política Indígena y Apoyo a las Comunidades Aborígenes y su Decreto Reglamentario No $155 / 89$, que a su vez reglamenta la creación del Instituto Nacional de Asuntos Indígenas (INAI); la Ley No 24.071, ratificatoria del Convenio No 169 de la Organización Internacional del Trabajo sobre Pueblos Indígenas y Tribales en Países Independientes, que promueve "el respeto por las culturas, las formas de vida, las tradiciones y el derecho consuetudinario de los pueblos indígenas y tribales" y destaca la conciencia de su identidad indígena o tribal como criterio fundamental para determinar los grupos a los que se aplican las disposiciones del Convenio y la Ley No 24.375 que aprueba el "Convenio de diversidad Biológica" en el año 1994.

El INAI, institución encargada de ejecutar las políticas en relación a poblaciones indíge-

bia, Editorial Universidad del Cauca, Cauca, 2004, p. 271.

4. BRIONES, Claudia, La alteridad del "cuarto mundo". Una reconstrucción antropológica de la diferencia, Ediciones del Sol, Buenos Aires, 1998. 
nas, ha ido creando diferentes programas que atienden a lineamientos específicos. En 1996, la Resolución del INAI No 4811/96 establece los requisitos para la inscripción de las $\mathrm{Co}^{-}$ munidades Indígenas en el Registro Nacional de Comunidades Indígenas (RENACI). En el 2004, ${ }^{5}$ se establece la conformación del Consejo de Participación Indígena (CPI) y el Programa de Fortalecimiento Comunitario y Acceso a la Justicia. ${ }^{6}$ En relación al problema territorial, en el año 2006 se sanciona la Ley No $26.160^{7}$ que declara la "Emergencia Territorial en materia de posesión y propiedad de las tierras que tradicionalmente ocupan las comunidades indígenas" y su Resolución de INAI 587/07 que establece la aplicación del Relevamiento Territorial de Comunidades Indígenas (RETECI). Con respecto a las formas de organización política y a través de la Resolución del INAI 328/10 se crea el Registro Nacional de Organizaciones Indígenas (RENOPI).

Este conjunto de legislaciones, disposiciones y acciones concretas expresan, en primer lugar, una conceptualización precisa sobre "lo indígena" del Estado argentino. Como mencionáramos, existe acuerdo con los lineamientos conceptuales vertidos por los organismos internacionales, pero eso no anula las particularidades estatales. En este punto debemos distinguir los niveles de análisis: una cosa es la construcción discursiva pública sobre esa conceptualización, otra su resultado en la concreción de políticas específicas y otra la esfera de aplicación real y los efectos (deseados y no deseados) en los colectivos y sujetos indígenas. Se

5. Mediante Resolución del INAI No 152/2004 y su modificatoria No 301/2004

6. Mediante Resolución del INAI 235/04.

7. Y, también, su prórroga, la Ley № 26.554 . impone entonces analizar la correspondencia entre estos planos diferentes de funcionamiento para acercarnos a responder lo enunciado: si, tras el postulado del reconocimiento de la pluralidad étnica, los mecanismos de ejecución utilizados son coherentes con el mismo, o pueden transformarse en procesos determinados por la violencia epistémica e institucional, con efectos concretos sobre los sujetos indígenas y sus luchas políticas.

Con respecto al concepto de violencia institucional, los acercamientos son múltiples y han sido abordados preferentemente por los profesionales del derecho. Los usos más generalizados se relacionan con los procesos de prevención, judicialización, corrección y ejecución penitenciaria, o con las instituciones con monopolio del uso de la fuerza como la policía, o con efecto sobre sectores poblacionales especialmente vulnerables como niños/as y adolescentes y mujeres. Pero también se entiende que la violencia institucional se encuentra estrechamente vinculada con la existencia del Estado y sus procesos de institucionalización, violentos en sí mismos ya que implican la violación del orden familiar, comunitario y subjetivo. ${ }^{8}$ Es decir, se trata de "un tipo de violencia que brota desde instituciones formales del Estado, o de sus ordenamientos funcionales, y que por ello mismo se encontraría cubierta de un manto de 'legitimidad". 9

8. CASOLA, Laura y MONASTEROLO, Natalia, "Hacia un nuevo concepto de violencia institucional. El ejercicio de la violencia a través de los sistemas de prevención, corrección y ejecución penitenciaria”, 2011. Disponible en http://estudiojuridicobritosferreyra.blogspot. com.ar/2011/04/hacia-un-nuevo-concepto-de-violencia. html [Consulta: el 20 de abril de 2013].

9. DOZ COSTA, Josefina, "Violencia institucional y cultura política”, en Cuadernos de la Facultad de Humanidades y Ciencias Sociales. Universidad Nacional de Jujuy, San 
Ciertas instituciones expresan su violencia de modo más evidente; en el caso particular que aquí analizamos, sin embargo, se requiere de un análisis un poco más profundo para hacerla manifiesta, ya que la violencia implícita en los mecanismos del INAI se encuentra opacada por un complejo discurso "inclusivo" " $\mathrm{y}$ respetuoso". A modo orientativo diremos entonces que, para este trabajo, caracterizaremos la violencia institucional como la red de mecanismos formales y burocráticos que, puestos en marcha con el fin de ejecutar una serie de políticas estatales en el área, terminan resultando ajenos a los sujetos de los que se ocupa y produciendo efectos diferentes a los que se explicitan como los objetivos de los programas.

En estos términos, la violencia institucional se encuentra profundamente ligada a la violencia epistémica, que debido a su ejercicio menos visible puede ser más difícil de determinar, a pesar de ser tan efectiva como otros tipos más explícitos. Podemos considerar distintas formas de ejercerla: la negación o apropiación de los saberes de los Pueblos originarios -una de las formas colonialistas de expropiación cultural más evidentes- o la imposición de conceptos, términos y acciones -realizadas durante siglos por el poder hegemónico y con el sustento funcional de la academia-. En palabras de Aníbal Quijano, esta "forma silenciosa de genocidio intelectual" debe ser puesta en cuestión y deconstruida, para identificar y descolonizar el conocimiento, cuestionar términos y metodologías, e incluso reconocer en los propios discursos de los Pueblos originarios "la letra de los dominadores". ${ }^{10}$ Nos interesa tener

Salvador de Jujuy, 2010, № 38, pp. 145-168.

10. QUIJANO, Aníbal, "Colonialidad del poder, cultura y conocimiento en América Latina”, en Dispositio, Michi- en cuenta aquí cómo esa colonialidad epistémica sobre lo indígena opera en el plano de las políticas públicas, efectivizada a través de sistemas formales y burocráticos, pero oculta bajo un manto de respeto a la diversidad y a las formas culturales.

Ambos tipos de violencia son parte de un entramado discursivo que proviene del marco regulador del Estado. Según la lectura de Foucault que hace Butler,

los sistemas jurídicos de poder producen a los sujetos a los que más tarde representan. Las nociones jurídicas de poder parecen regular la esfera política únicamente en términos negativos, es decir mediante la limitación, el control y hasta la "protección de las personas”... No obstante, los sujetos regulados por esas estructuras, en virtud de que están sujetos a ellas, se constituyen, se definen y se reproducen de acuerdo con las imposiciones de dichas estructuras. ${ }^{11}$

En otras palabras, el problema de la sujeción y de la regulación implica tener en cuenta dos advertencias derivadas del pensamiento de Foucault:

1) el poder regulador no sólo actúa sobre un sujeto preexistente, sino que también labra y forma al sujeto; y 2) estar sujeto a un reglamento es también estar subjetivado por él, es decir, devenir como sujeto precisamente a través de la reglamentación. ${ }^{12}$

Los señalamientos de Butler sobre el poder

gan, 1999, V. XXIV, No 51, p. 4.

11. BUTLER, Judith, El género en disputa, Paidós, Barcelona, 2007, p. 47.

12. BUTLER, Judith, Deshacer el género, Paidós, Barcelona, 2006, p. 68. 
performativo del discurso (aunque orientados a temas de género) son pertinentes para este trabajo: nos interesa saber cómo el sistema de regulación que surge de la norma estatal sobre "el ser indígena" produce subjetividades y transformaciones en esos sujetos y su desarrollo político.

\section{Procedimiento del RENACI}

Pero ¿cómo pueden los procesos de ejecución e implementación de los registros y programas nacionales, configurar modos de control de los procesos etnogenéticos? Revisemos sus objetivos y los requisitos formales que implican.

Como mencionáramos, el Registro Nacional de Comunidades Indígenas (RENACI) fue creado en 1996 por Resolución del INAI No 4811/96 ${ }^{13}$. Según el Instituto, en la actualidad se lleva inscriptas aquí 1.333 comunidades, pertenecientes a aproximadamente 30 pueblos originarios. Los objetivos son:

promover la inscripción de las Comunidades Indígenas y asistirlas para que realicen las tramitaciones y acrediten las circunstancias que esa inscripción requiera; mantener actualizada la nómina de Comunidades Indígenas inscriptas y no inscriptas; coordinar su acción con los institutos de asuntos indígenas existentes en las jurisdicciones provinciales y municipales; establecer registros locales en el interior o convenir con las provincias su funcionamiento. ${ }^{14}$

13. Para un análisis profundo y en perspectiva etnográfica del texto de esta resolución, ver G.E.L.I.N.D, "Etnografía del discurso jurídico sobre lo indígena. La resolución 4811/96 desde la pragmática”, en Publicar, 1999, Año VII, No 8.

14. Fuente: Resolución del INAI No 4811/96.
Pero el fin más importante de este registro es posibilitar el acceso a una Personería Jurídica, lo que implica la obtención del reconocimiento del Estado nacional, que se compromete a "considerar con valor jurídico" a las comunidades que logren acreditar su "pertenencia a un grupo aborigen", como colectivos sociales con derechos específicos, en tanto Pueblos originarios. En este sentido,

obteniendo la personería, pueden accionar legalmente en defensa de sus derechos, frente al Estado o particulares (por ejemplo en casos de recuperación de tierras, o reclamos por una educación bilingüe). Además, de esta manera las comunidades pueden recibir apoyo del Estado, o de organizaciones no gubernamentales (ONG) nacionales e internacionales, para promover su bienestar económico, sus proyectos culturales, organización, educación, etcétera, sin necesidad de intermediarios. ${ }^{15}$

Las personerías jurídicas constituyen a las comunidades como sujetos de derecho con carácter público no estatal, como estructura institucional propia de carácter político, económico, cultural y social, operativizando así lo expuesto en la reforma constitucional de 1994. Sin embargo, la contrapartida de esto plantea un problema: ¿Cómo acceden a estos derechos aquellas comunidades que no puedan/ quieran inscribirse? La preexistencia no aparece aquí como una condición que se acepte per se, sino que debe ser reconocida por el Estado a través del "otorgamiento" de ese derecho en la forma de la personería. Es decir, se trata de una "preexistencia normalizada" según las reglas de la ciudadanía nacional.

15. Ibidem 
E1 RENACI, como mecanismo específico que pone en acto la ejecución de esta normalización y "reúne las pruebas" para ella, impone requisitos de diversa índole para la inscripción: datos generales, como nombre y ubicación geográfica de la Comunidad; datos de tipo censal, como una nómina de los integrantes, con sus grados de parentesco; una reseña que acredite su origen étnico-cultural e histórico, con presentación de la documentación disponible al respecto; y datos políticos, como la descripción de sus pautas de organización, los medios de designación y remoción de sus autoridades y los mecanismos de integración y exclusión de sus miembros. Según figura en la resolución del INAI, el proceso de inscripción consiste en

una única presentación que no requiere actualización de la documentación, excepto que así lo establezca la misma Comunidad en su documento constitutivo. Luego de cumplidos los requisitos la Comunidad es inscripta a través de resolución fundada del Presidente del INAI. La vigencia de la personería jurídica se mantiene mientras siga existiendo la comunidad y se respeten las pautas de organización descriptas por la misma comunidad.

Sin embargo, esta "única presentación" no es tan sencilla. Desde los inicios del registro, las distintas comunidades que tramitaron su personería jurídica han experimentado inconvenientes en su tramitación. Por un lado por la excesiva extensión temporal de los trámites -efecto habitual de los mecanismos burocratizados- que se hace muy problemático para aquellas comunidades que se encuentran más alejadas espacialmente de los organismos. Esto se manifiesta, en primer lugar, en la dificultad de contactar a los representantes-funciona- rios que explicitarán y orientarán sobre cómo proceder con las distintas etapas del trámite (recordemos que uno de los propósitos planteados indica la asistencia en este tema). Esta ausencia de acompañamiento ha provocado que muchos informes, requisitos o escritos presentados por las comunidades, hayan sido devueltos para ser revisados o confeccionados nuevamente, por no ajustarse a las formas y contenidos esperados. ${ }^{16}$

Además, los inconvenientes en los envíos a Buenos Aires provocan que se extiendan los plazos de ejecución y resolución, que en algunos casos alcanzan más de dos años de espera, dificultando y retrasando la obtención de la personería y por lo tanto, del acceso a los derechos. Estas complicaciones y tardanzas han sido tan significativas que incluso alguna comunidad ha "aceptado" cambios en su propio nombre (aspecto central para su identidad) que "por error" -o quizás por desatención o desinterés- fueron inscriptas de manera equivocada, ${ }^{17}$ sólo por no padecer nuevamente el proceso de inscripción y los tiempos institucionales, contrarios a la urgencia de los conflictos territoriales. ${ }^{18}$ Como resultado de estas

16. En el caso de Rio Negro, por ejemplo varios expedientes de personerías jurídicas correspondientes a comunidades mapuche (Maliqueo; Buenuleo; Sierra Paileman, ente otros) han sido devueltas porque la "reseña histórica" o la nómina de "funciones o roles" dentro de la comunidad estaba, a los ojos estatales, poco desarrollada o "incompleta”. Nos preguntamos: ¿Cómo se mide la completitud en el relato de la historia de un pueblo?

17. Es el caso de la comunidad mapuche inscripta como Kume Peuque Mapuche, pero cuyo nombre correcto es Kume Peuque Mapu, con una diferencia de sentido importante, ya que -en palabras del lonko Jose Collueque"nosotros queríamos decir que es la tierra la que tiene un corazón bueno y no la gente"

18. Hay que tener en cuenta que los nombres de las comunidades no surgen de elecciones caprichosas sino 
complicadas experiencias y de las consecuentes demandas de descentralización que las comunidades expresaron a sus representantes, en la provincia de Rio Negro se ha creado un registro provincial, ${ }^{19}$ con el fin de acortar distancias y tiempos de proceso, objetivo que de todos modos, no siempre ha sido alcanzado.

Estas complicaciones de funcionamiento efectivo implican un alto grado de violencia institucional. $\mathrm{Al}$ no poderse contenerse las necesidades de los sujetos para la concreción de esos trámites, ni ofrecer los recursos para realizarlos, se los deja subsumidos a las dinámicas de la burocracia estatal pero en una relación de fuerte dependencia, ya que es en el cumplimiento de estos trámites que radica la única posibilidad que el Estado ofrece para el acceso a ciertos derechos. Por otro lado, los tiempos burocráticos se imponen sobre la realidad de las necesidades, en un momento de mucho conflicto en los territorios donde las comunidades habitan.

Centrémonos ahora en las lógicas de control subyacentes y la violencia epistémica que las sustentan. En primer lugar, los miembros de las comunidades deben "acreditar su origen étnico-cultural e histórico" con la "documentación disponible al respecto". Queremos

que en general son significativos y guardan relación con aspectos culturales, tradicionales, ideológicos, etc. Por lo que un cambio de nombre no constituye un error menor, sino que pone en juego cuestiones profundas que implican aspectos epistémicos que son vulnerados por el mecanismo burocrático.

19. En el caso particular de Rio Negro, se ha implementado registro de carácter provincial a través del Consejo de Desarrollo de Comunidades indígenas (CODECI), que ha adoptado la forma de "cogobierno" entre gobierno provincial y organizaciones indígenas. Este tipo de descentralización es, sin embargo, particular, ya que en el resto de las provincias no se ha implementado. destacar aquí dos cuestiones centrales: la primera es el desconocimiento a la autoadscripción como criterio suficiente, indicado por el Convenio 169 de la OIT. Como contracara, el Estado asume la potestad de "evaluar" la documentación presentada para otorgar él mismo esa adscripción, hecho que destaca el control centralizado sobre los procesos políticos y etnogenéticos.

En segundo lugar, resulta profundamente contradictorio el pedido de "documentos", que evidencia un alto grado de subestimación del rol del relato oral como fuente, completamente devaluado y sin peso cuando es en realidad uno de los medios fundamentales en la construcción de la historia y la identidad indígena. Hay que tener en cuenta además que esos "documentos disponibles" se limitan en muchos casos a actas de inspección, permisos precarios, actas de desalojo, registros censales, etc., es decir que no fueron producidos por las comunidades sino, por el contrario, por instituciones que históricamente tendieron a la invisibilización de estos grupos. La acreditación documentada es un problema importante, no sólo por su lugar central como requisito del trámite de registro, sin el cual no se puede acceder a los derechos fundamentales, sino porque surge de criterios que invalidan la premisa de respeto a la pluralidad y a las formas de expresión propias de los distintos grupos, para estructurarlas según la lógica del documento escrito y oficializado, exactamente lo opuesto al modo de construcción de la historia y de la identidad de la mayoría de los grupos indígenas.

Por último, en el afán de registrar las comunidades existentes y controlar de este modo el acceso a las garantías del derecho, el sistema resulta completamente ineficiente en aquellos 
casos en los que los Pueblos tienden a tipos de organización más "inestables", por ejemplo por dinámicas de movilidad frecuentes o de creación permanente de nuevas comunidades. Y tampoco logra ser inclusivo en cuanto a aquellos Pueblos que, en los territorios, tienen poco contacto con el sistema de comunicación y representación del Estado. En otras palabras, se trata de un registro parcial, que funciona mejor en tanto más cerca se encuentren las comunidades de compartir, comprender o acceder a las lógicas estatales y sus "beneficios". El resto, no tiene "existencia jurídica".

\section{Procedimiento del RETECI}

El problema fundamental de las comunidades indígenas en nuestro país es la imposibilidad de recuperación de su territorio, expropiado primero por la colonia española y luego por el Estado nación en el siglo XIX. Es entonces uno de los objetivos del INAI, a solucionar a través de mecanismos específicos destinados a tal fin. A raíz de los múltiples conflictos y procesos de desalojo que deben enfrentar las comunidades a partir de sus acciones políticas territoriales, en el año 2006 se sanciona la ley 26.160 de Emergencia Territorial, con el objetivo de suspender ${ }^{20}$ provisoriamente los desalojos ${ }^{21} \mathrm{y}$ realizar en forma para-

20. Es necesario destacar, tal como expone Claudia Briones, que la "mera suspensión (de los desalojos) lejos todavía nos deja de honrar esa cláusula constitucional de asegurarles a todas ellas la posesión y propiedad de sus tierras" en BRIONES, Claudia, "La Nación Argentina de cien en cien: de criollos a blancos y de blancos a mestizos.", en NUN, José y GRIMSON, Alejandro (compiladores) Nación y diversidad. Territorios, identidades y federalismo. Edhasa y Secretaría de Cultura de la Nación, Buenos Aires, 2008, p. 36.

21. Inicialmente esta protección se planteaba hasta el año 2010, extendiéndose luego hasta fin del 2013. En este lela el relevamiento de las tierras ocupadas por las comunidades de todo el país, con el fin de ponerlas en relación con los territorios totales reclamados por los Pueblos originarios. ${ }^{22}$ Esto se lleva a cabo a través del programa de Relevamiento Territorial de Comunidades Indígenas (RETECI). Formalmente, el programa tiene como objetivos generales

crear las condiciones para la implementación de los derechos constitucionalmente reconocidos con relación a las tierras y territorios; instrumentar el reconocimiento constitucional de los territorios de las comunidades de los pueblos indígenas que habitan en Argentina; garantizar la participación indígena a través del CPI en la elaboración, ejecución y seguimiento de los proyectos que deriven del Programa y realizar el relevamiento técnico, jurídico y catastral de la situación dominial de las tierras ocupadas por las comunidades indígenas. ${ }^{23}$

Al estar la ley 26.160 focalizada en la suspensión de los desalojos, el RETECI -que depende de la Dirección de Tierras- tiene como objetivo el relevamiento puramente territorial y deja en segundo plano, o como información complementaria, los aspectos económicos y sociales de las comunidades. Tampoco tiene en cuenta el pasado -en relación a los territorios perdidos- o la proyección hacia futuras recuperaciones: se presenta como una especie de "fotografía", sobre la situación territorial actual. Esto demuestra los límites tanto de la ley como del programa, ya que si bien se ha logra-

momento, se discute una nueva ampliación del plazo, en vistas de que aun no se han concluido los procesos de relevamiento territorial comenzados en 2009.

22. BRIONES, Claudia, “La Nación Argentina...”, Op. Cit., pp. 35-62.

23. Disponible en: http://www.desarrollosocial.gob.ar/ Uploads/i1/Institucional/Ley 26160.PDF 
do la suspensión de una parte de los desalojos -menos frecuentes luego de su sanción- siguen sin existir garantías reales de reconocimiento sobre el territorio hacia las comunidades que lo habitan y construyen cotidianamente, en muchos casos desde hace siglos. ${ }^{24}$

En cuanto a la ejecución del programa, los requisitos a cumplir por el "listado de comunidades a relevar" 25 para completar el proceso de relevamiento son, según estipula el instructivo del RETECI:

la confección de una narrativa y croquis del territorio que en forma tradicional, actual y pública ocupa cada comunidad relevada, realizado por la propia comunidad y georreferenciado; la mensura y/o levantamiento territorial del o de los territorios de la $\mathrm{Co}^{-}$ munidad inscriptos ante el organismo provincial competente; el estudio de títulos del levantamiento territorial; los resultados del Cuestionario socio-comunitario; el relevamiento de los aspectos socio-productivos y recursos naturales existentes en el territorio de la Comunidad; la narración de la historia de los procesos que determinaron la situación territorial actual de la Comunidad; $\mathrm{y}$ el desarrollo de las estrategias jurídicas correspondientes a la condición dominial que ostente el territorio relevado tendiente a la efectiva instrumentación del reconocimiento constitucional. ${ }^{26}$

24. GUIÑAZU, Samanta, "Agencia y resistencia indígena. Un análisis sobre el relevamiento territorial de comunidades indígenas en la provincia de Rio Negro", en Actas del Tercer Congreso Latinoamericano de Antropologia ALA 2012, Santiago de Chile, 2012.

25. Listado que debe ser elaborado por el organismo de ejecución provincial, para establecer una lista de comunidades a relevar -dando cuenta de la ubicación geográfica, cantidad de personas que conforman la comunidad, entre otras-.

26. Fuente: Ministerio de Desarrollo Social de la Nación:
Estas "producciones" son realizadas a partir de un proceso llevado a cabo, en las diferentes provincias, por Equipos Técnicos Operativos (ETO), en conjunto con representantes indígenas. Una vez terminados conforman -junto a las actas de aceptación de participación en el RETECI firmadas por las autoridades de cada comunidad- la llamada "Carpeta Técnica" que, luego de aprobada mediante resolución del INAI, tomará carácter de documento público.

A lo largo del proceso de relevamiento se han identificado y planteado distintas problemáticas en torno a la planificación, proyección y difusión del RETECI. Muchos se relacionan con cierta discrepancia entre los tiempos reales necesarios para cumplimentar la gran cantidad de requisitos exigidos, y los tiempos institucionales impuestos verticalmente desde el INAI (aunque a diferencia de lo enunciado en el apartado anterior, aquí es la urgencia la que rige los trámites) que no se ha logrado revertir, pese a las reformulaciones exigidas por los miembros y representantes originarios.

Como resultado de esta incompatibilidad, se manifiestan en forma conjunta los dos tipos de violencia que nos ocupan en este trabajo. La necesidad de intervenir en este programa -por el momento la única respuesta del Estado a los reclamos territoriales- implica que por no "quedarse afuera" haya que someterse nuevamente a los tiempos del Estado, en este caso apresurando las etapas del procedimiento en desmedro de la profundidad necesaria para este trabajo. La urgencia también ha apresurado el debate mismo, al interior de las comunidades, sobre si aceptar o no lo que implica "ser relevados", violentándose de este modo las

http://www.desarrollosocial.gov.ar/ 
distintas modalidades de discusión que cada pueblo y comunidad tiene y utiliza, y por lo tanto también su conceptualización sobre el uso del tiempo, diferente y específico en cada caso. En este sentido, la aplicación impulsiva del programa y las fallas de difusión por la urgencia, han vulnerado en muchos casos -entre otras cosas- el postulado de "consentimiento, libre, previo e informado" que indica el Convenio 169 de la OIT. ${ }^{27}$

Es necesario analizar, de acuerdo al concepto de violencia epistémica, las implicancias que acarrea un relevamiento territorial sobre la ocupación "actual, tradicional y pública". ¿Qué se entiende por estas categorías? Para el programa, el problema del territorio no puede ser respondido en términos topográficos o histórico geográficos, sino que hay que partir del concepto de "territorio tradicional" o "etnoterritorio". Sin embargo, ese territorio tradicional se reconstruye a partir del actual do-

27. Nuevamente, ejemplificamos con el caso de la comunidad Kume Peuque Mapuche, que inscripta erróneamente en el RENACI sufrió que los mecanismos burocráticos se impusieran sobre su propia identidad. Manifestando a los técnicos del RETECI su voluntad de "aprovechar esta instancia para corregir el nombre de la comunidad", el pedido - con los argumentos que lo sustentaban- fue enviado al INAI junto a la Carpeta Técnica. Ésta fue, sin embargo, devuelta para su corrección ya que el nombre que figuraba en el croquis realizado por la comunidad, en la narrativa y en el informe histórico (es decir, el nombre original), no coincidía con el nombre registrado en el RENACI. La solución fue figurar en su relevamiento nuevamente con el nombre "erróneo", teniendo que explicar el verdadero, elegido por la comunidad, en una mera "nota al pie". Aclaramos que el mencionado croquis, uno de los requisitos a presentar, es un mapeado manual realizado por la comunidad y georreferenciado (es decir, confrontado con los datos técnicos de GPS que ofrecen los mapas, realizados por los agrimensores). El hecho de la corroboración de los datos del saber comunal por los profesionales grafica la diferencia de jerarquía entre ambos saberes, implícita en este acto de control. minio de tierras de cada comunidad -al 2006, fecha de sanción de la ley 26.160-, teniendo en cuenta que el concepto de territorio tradicional es multidimensional -abarcando lo político, social, económico, cultural y religioso- y que "la delimitación de sus límites y fronteras requiere de la consideración integrada de todos sus aspectos", y de la integración del saber de la comunidad sobre cada variable y su expresión espacial. Pero esto debe, de todos modos, ser refrendado por producciones bibliográficas con el fin de "reconstruir el territorio que en la actualidad ocupan, el que antaño poseyeron y el que se busca recrear".

Ciertamente la caracterización de lo tradicional busca el anclaje en el pasado desde el presente, pero es lo suficientemente amplia y ambigua como para dejar un espacio abierto para el debate. Pero lo más significativo es la explícita exclusión del concepto de territorio "ancestral" (término que muchas comunidades reclaman como más acertada para definir su relación con el territorio), por momentos incluido en el tradicional y por otros sólo posible de reconstituir a partir de la perspectiva histórica, para compararlos con las jurisdicciones actuales y entender los procesos de reducción. "Tradicional" permite un espacio suficiente de ambigüedad que sin reconocer explícitamente lo ancestral, niega a la vez el paso del tiempo en la búsqueda de prácticas prístinas. También menciona los "procesos de reducción" territorial omitiendo explicaciones sobre la violencia física y simbólica, la desarticulación, invisibilización y obliteración sufridas por los Pueblos originarios, así como las estrategias de reinvención y resignificación con las que éstos responden. ${ }^{28}$

28. GUIÑAZU, Samanta y COHEN, Sebastián, "Construyendo territorialidades. Nuevas y viejas formas de 
En términos de resultados concretos, surgen varias preguntas. En primer lugar ¿qué sucede con lo recuperado o en vistas a recuperarse luego de la fecha del relevamiento? $\mathrm{O}$ en otras palabras ¿existe garantía de recuperación o restitución formal sobre aquello no ocupado "actualmente" (para el momento del relevamiento), pero que "se busca recrear"? ¿Y sobre las tierras ancestrales que "se han perdido"? Relevar, ¿ significa el comienzo de la restitución, o sólo constituye un estado de situación?

Por último, se entiende por "público" a toda aquella información, acto o hecho de conocimiento público que puede ser consultado o verificado por cualquier persona, por ejemplo documentos administrativos, actas, información mediática o de divulgación. Ocupar un territorio de manera pública para el Estado, parece entonces depender de que existan este tipo de documentos, o que los "signos" de la ocupación sobre el territorio sean evidentes de acuerdo a su propia lógica. ${ }^{29}$ Esta forma de concebir la ocupación es limitada y deja fuera tanto a aquellos que habitan espacios muy alejados de los centros urbanos, cuya ocupación no se ajusta al carácter "público" sino que responde a otros criterios de pertenencia, como a aquellos a quienes -aún ocupando- se les niega ese carácter por cuestiones diversas (por ejemplo, conflictos judiciales).

La triple opción conceptual $-y$ clasificatoria- que propone el programa, constituye un intento de subsumir la complejidad que el concepto de territorio tiene para los distintos Pueblos originarios a un marco pretendidamente amplio, que toma en cuenta diversos

pensar, sentir y habitar el territorio", en Publicar, 2012.

29. Ibídem. criterios. Sin embargo, esos criterios responden a la lógica hegemónica estatal y no a la visión indígena. Esta diferencia manifiesta los marcos epistémicos opuestos de los que surgen ambas conceptualizaciones. Que los criterios respondan más a uno que al otro, revela la desigual relación de fuerzas entre ambos. Del mismo modo, el procedimiento plantea un sistema de trabajo conjunto con las comunidades, a partir de distintas metodologías, para armar la documentación de la Carpeta Técnica ${ }^{30}$. Pero los elementos aportados por las comunidades son ordenados, clasificados, analizados y confrontados por el saber profesional. De este modo, los técnicos operan formas de traducción sobre

30. En este sentido, cabe mencionar que por medio del trabajo conjunto entre los Equipos Técnicos Operativos (ETOs) y los miembros de las comunidades participantes del relevamiento, se han buscado estrategias para poder dar cuenta en las Carpetas Técnicas de situaciones/realidades que no estaban contempladas inicialmente y por lo tanto impedían reflejar las particularidades de cada territorio. De este modo se acuñaron categorías alternativas tales como "Territorio de la Memoria" y "Territorio en Conflicto", que fueron presentadas ante el INAI y aceptadas para ser utilizadas tanto en los Informes Histórico-antropológicos como en los Dictámenes legales y en la cartografía. "Territorio de la Memoria" remite a aquel espacio territorial que no puede ser relevado cartográficamente ya que no da cuenta de la ocupación actual, tradicional y publica, pero sí puede ser incorporado a modo "informativo" en el informe histórico antropológico a través de los relatos de los miembros de la comunidad. "Territorio en conflicto" es una categoría elaborada con el fin de explicar la particularidad de muchos de los territorios comunitarios que aun contando con posesión actual, tradicional y pública, presentan conflictos con terceros por esta posesión. La historia de estos conflictos, recuperada en los Informes Histórico- antropológicos, serviría de insumo para la elaboración de estrategias legales específicas para la resolución de dichos conflictos. Estas iniciativas, implementadas en la provincia de Rio Negro, han servido de base para el trabajo en otros ETOs (por ejemplo en Santa Cruz) o relevamientos centralizados implementados directamente por el INAI, sin la intervención del ETO provincial, como el caso de Las Huaytekas (Rio Negro). 
ese corpus de información, de acuerdo a los procedimientos reglamentados por el programa. ¿Cómo se comprende este ordenamiento si no es como resultado de una relación despareja de fuerzas? El tema del territorio constituye el nudo central de la problemática indígena actual. ¿Pueden los indígenas tener la seguridad de que el Estado comprende lo que significa para ellos su territorio, si no pueden ser escuchados en sus propios términos, sin que medie traducción?

\section{Procedimiento del RENOPI}

El último procedimiento que nos ocupa es el Registro Nacional de Organizaciones de Comunidades Indígenas (RENOPI), creado por el INAI según resolución 328/2010, con los siguientes objetivos:

Reconocer las organizaciones que nuclean a las comunidades de los pueblos indígenas, que en la actualidad están surgiendo: inscribir la personería jurídica de las organizaciones de las comunidades de los pueblos indígenas; mantener actualizada la nómina de las mismas; coordinar su acción con el RENACI y con los demás registros existentes en las jurisdicciones provinciales $y$ municipales. ${ }^{31}$

En este mismo documento se expone que, desde este Registro, se entiende como "Organizaciones de los Pueblos Indígenas" a aquellas que ostenten la representación mayoritaria de las comunidades indígenas de un mismo o de distintos Pueblos indígenas a nivel provincial, regional o nacional, y que dichas comunidades deberán tener registrada su personería jurídica en el RENACI.

31. Fuente: Legislación Nacional 328/2010.
El "fortalecimiento" de las organizaciones territoriales por medio del otorgamiento de una personería jurídica propia tiene como resultado que las organizaciones registradas se erigen en "interlocutores obligados y legítimos de la política pública local, provincial o nacional, pues representan a un pueblo en su conjunto". ${ }^{32}$ Además, la inscripción habilita su integración en espacios de consulta y representación indígena -que en su mayoría dependen también del INAI-. Para registrarse,

se debe presentar una nota de solicitud, elevada por sus autoridades; una copia certificada del acto administrativo que acredite su inscripción en el organismo provincial competente; una copia certificada de la nómina de autoridades vigentes; una copia certificada del estatuto o pautas comunitarias presentados en el marco del organismo provincial competente, si los hubiere. ${ }^{33}$

Para el registro existen tres tipos diferenciales $-1^{\circ}, 2^{\circ}$ o $3^{\circ}$ grado- según el grado de representatividad que acrediten las organizaciones que aspiren al reconocimiento, que surge del porcentaje de organizaciones de un mismo Pueblo que representen. ${ }^{34}$ Legitiman-

32. Ibídem.

33. Ibídem.

34. "Art. 6: Se entenderá por Organizaciones de Pueblos Indígenas de Primer Grado a aquellas que integren la representación de comunidades indígenas registradas de un mismo pueblo dentro del ámbito de una única provincia. Se deberá acreditar que las comunidades constituyan al menos el 60\% (sesenta por ciento) del total de comunidades del pueblo de pertenencia en esa provincia. Asimismo, el Presidente del Instituto Nacional de Asuntos Indígenas podrá autorizar el registro de una organización de distintos pueblos en una misma provincia. Se deberá acreditar que las Comunidades constituyan al menos el 60\% (sesenta por ciento) del total de Comunidades de cada Pueblo de pertenencia. Art. 7: Se entenderá 
do ese grado, deben presentarse además el acta de la Organización con la presentación de su nombre, Pueblo indígena en el que se reconoce, provincia en la que habita, domicilio legal, nómina de las comunidades integrantes con acreditación del registro de su personería jurídica y nómina de autoridades. Esta acta deberá ser ratificada por las autoridades de las comunidades integrantes de la organización, en Asamblea y con la asistencia de un delegado del Registro Nacional. También deben clarificarse las pautas de organización, las facultades de las autoridades, la duración de los mandatos y los mecanismos de designación y remoción de los mismos y además los mecanismos de inclusión, renuncia y exclusión de las comunidades-miembros. Cada una de ellas debe presentar además el acta comunitaria que exprese su adhesión a la organización, debidamente refrendada por la Asamblea Comunitaria.

Hay que destacar que el RENOPI es una propuesta incipiente y sus avances y resultados aún son parciales, lo que limita la profundidad del análisis. Sin embargo, queremos plantear algunas dudas que surgen del Estado de cosas indicado por los documentos de reglamentación y procedimiento, que son parte de un trabajo a futuro. En primer lugar y teniendo en cuenta que la creación de este registro responde a demandas concretas por parte de los actores indígenas, resulta necesario indagar profundamente si esta "respuesta" estatal refleja efectivamente, las demandas de origen; o

por Organizaciones de Pueblos Indígenas de Segundo Grado aquellas que integren al menos el 60\% (sesenta por ciento) de las organizaciones de primer grado de un mismo pueblo inscriptas en el Registro. Art. 8: Se entenderá por Organizaciones de Pueblos Indígenas de Tercer Grado aquellas que integren la representación de Organizaciones de Pueblos de Segundo Grado inscriptas en el Registro, que habitan en por lo menos 14 (catorce) provincias. (INAI, res. 328/2010) si, por el contrario, las formas de organización planteadas como válidas por el registro son otro resultado de la "traducción" que el Estado realiza sobre las demandas indígenas.

En este sentido, podemos señalar de manera preliminar, que la gradación de las organizaciones planteadas en un tipo de registro diferencial, implica la aplicación de una lógica simplemente cuantitativa, sin dejar en claro en qué medida esto afecta el rol de las organizaciones respecto al diálogo con el Estado, por ejemplo si las consideradas más "representativas" - de $1^{\circ}$ grado- adquieren prerrogativas particulares por su condición. Otro punto a tener en cuenta es que, a pesar de que el registro surge como respuesta a reclamos indígenas de reconocimiento a sus modos de organización, a la vez impone un ordenamiento que responde a pautas propias y avanza progresivamente hacia el encorsetamiento de los diversos modos de organización políticos indígenas en un sistema representativo y de grados, pero único. El riesgo es la reducción numérica y la jerarquización de una "cúpula" de representantes indígenas que serán "aceptados" por el Estado para el diálogo. Esto implica un alejamiento de las realidades territoriales de las comunidades, que se ven mediatizadas ya no sólo por los representantes de las comunidades sino también por organizaciones más amplias, situación que puede producir fricciones y desavenencias en los territorios.

En otras palabras, el derecho adquirido de las organizaciones territoriales a la existencia y a la escucha por parte del Estado se pone en riesgo si el sistema de diálogo se cierra en torno a unos pocos representantes autorizados. En ese caso, las estructuras asamblearias y la búsqueda de consenso de base de las comuni- 
dades podrían perder valor respecto de estas estructuras, avaladas por el Estado. Para éste, monopolizar el diálogo con las organizaciones le evita esperar esos largos tiempos de debate y reducir el número de personas a discutir. Sin embargo, vehiculizar el acceso de las organizaciones al diálogo con el Estado según pautas preestablecidas y jerarquizadas puede ser problemático, en tanto se acercaría más a nuestro sistema político que a las formas indígenas, no respetaría los parámetros de diversidad y limitaría la autonomía en la construcción política.

\section{¿Burocratización de las lógicas de reconocimiento?}

Del análisis de los procesos de ejecución y funcionamiento de los tres programas mencionados, hemos analizado en cada uno de ellos, según los requisitos expuestos, tanto los problemas surgidos de la ejecución real como aspectos ideológicos asociados a ellos, de acuerdo a nuestro enfoque, desde los ejes de violencia institucional y epistémica. En el primer caso, podemos decir a modo general, que por un lado se manifiestan grandes contradicciones entre los tiempos técnicos e institucionales y los que manejan las comunidades indígenas. En segundo término, que tanto en la aplicación real y concreta de estos programas como en la idea de "reconocimiento" otorgado por el Estado, encontramos un sentido de homogeneización que desatiende las particularidades de cada pueblo y sus comunidades, imponiéndoles formas, categorías, y ordenamientos clasificatorios y jerarquizados.

En este sentido, podemos afirmar que las prácticas de los programas mencionados dan cuenta de un trinomio, compuesto por la bu- rocratización de los procesos de reconocimiento, la homogeneización y el desinterés por las particularidades y la imposición de categorías estatales sobre los indígenas. En esta conjunción identificamos las formas de violencia mencionadas como partícipes implícitas de la relación entre Estado y Pueblos. Si coincidimos en ver al Estado como el control del aparato de la violencia en sus distintas formas, no podemos dejar de señalar que esta relación es desigual y está regulada verticalmente por éste, aspecto que se opaca al presentarse discursivamente como un diálogo inclusivo en paridad de condiciones y al ser entendido por las comunidades como un logro y un reconocimiento genuino.

En primer lugar, siguiendo a Weber, ${ }^{35}$ entendemos por burocratización el proceso que remite a la generación de una compleja red de derechos y obligaciones, que lleva a la reducción de la eficiencia del "bureau" mismo, por preocuparse más por el mantenimiento de esta red, que por el cuidado del objetivo que pretendía alcanzar y para el que fue creado. En nuestro análisis, la identificamos como una forma de violencia institucional, que implica el pasaje de las demandas y reclamos genuinos a su formalización y traducción al lenguaje del Estado como única vía para su atención. A esto se suman formas de acción que obstaculizan y lentifican los trámites, demostrando lejanía e indiferencia respecto de la urgencia y necesidad que éstos significan para la resolución de algunos problemas.

Es interesante destacar, como parte constitutiva de esta burocratización, una especie

35. WEBER, Max, Economy and society: An outline of interpretive sociology, University of California Press, Berkeley y Los Ángeles, 1978, p. 223. 
de "autovalidación recíproca" de los requisitos entre registros y programas, que conforman entre sí un sistema intrínseco. Sumado a esto, podemos dar cuenta del ejercicio de un monopolio de los recursos de la expresión política legitimada, dentro de los cuales las categorías y prácticas regulan los reclamos y demandas dentro de formas precisas y encasilladas. De este modo, se suprimen u obstaculizan otras formas - no tan controlables- de vehiculizar estos reclamos. Por lo tanto, si bien se fomenta la creación y formalización de comunidades y organizaciones indígenas, de sus reclamos y solicitudes, la imposición de excesivos requisitos, formas y tiempos unilaterales limitan las posibilidades de acción-agentividad política dentro de los marcos estatales. Siguiendo a Restrepo, "las condiciones de emergencia de un sujeto político determinado, no garantizan su posible accionar político". ${ }^{36}$ En este sentido, el discurso "inclusivo" sobre la diversidad de formas organizativas y la agencia de los Pueblos originarios, no da cuenta nunca de que éstas sólo serán reconocidas si se adaptan a los límites que establece lo "indígenamente admitido", y si convierten sus reclamos a un idioma comprensible para la lógica estatal.

Surge entonces, en segundo lugar, el problema del desinterés y la homogeneización, que se evidencian en la falta de compromiso para que estos "procesos de reconocimiento" se acerquen realmente a las comunidades. De allí las falencias, en la difusión de los objetivos y formas, en la explicitación de alcances y limitaciones y en el acompañamiento y asistencia durante los trámites. Luego, en las devoluciones de trámites ya finalizados por no cumplir con la forma "correcta", o en las interminables

36.. RESTREPO, Eduardo, "Biopolítica y alteridad...", Op. Cit., p. 271. idas y vueltas. Frente a estas dificultades, muchas veces se prefiere llenar los formularios con contenidos formateados, contribuyendo también así a la homogeneización. Todo esto demuestra la brecha importante entre los objetivos discursivos que explicita el Estado (promoción del fortalecimiento de las comunidades y organizaciones, y asistencia en los procedimientos) y los resultados concretos, que muestran otra realidad.

Por último, y en relación a las formas de imposición de categorías, nombres e identidades en estos procesos, mencionaremos que los objetivos, requisitos, formularios y productos parecen orientarse según la lógica de la "demostración” de la condición de originarios, a través de fundamentaciones impuestas. Esto, como ya lo señaláramos, cuestiona severamente los criterios de "autoadscripción" reconocidos por el convenio 169 de la OIT, parámetro clave que rige nuestra legislación nacional, ya que por un lado la condición indígena requiere de documentos "probatorios" de distinta índole para ser reconocida y por el otro, porque las pruebas y fundamentaciones deben ajustarse a parámetros estereotipados sobre la forma aceptada de "ser indígena", elaborada e impuesta como real por el Estado. En este sentido, podemos decir que se exige una justificación de la indigenidad ${ }^{37}$ para pasar la "prueba

37. Según Stavenhagen, "el concepto de "indigenidad" sugiere una continuidad histórica entre la población indígena original y la que actualmente se identifica como descendiente directa de aquella. Esta continuidad puede ser genética (por reproducción biológica) y cultural (mantenimiento de formas culturales tales como la lengua y la religión que se derivan directamente del grupo originario)." Sin embargo "con frecuencia, independientemente de los orígenes y la continuidad biológica y cultural, es el resultado de políticas gubernamentales impuestas desde arriba y desde afuera. También es producto, las más de las veces, de un "discurso construido" por las emergentes 
de la legitimidad", siempre según las reglas hegemónicas.

De este modo, estos -y otros- procesos de "reconocimiento" establecen los límites y las formas en que deben plantearse las demandas, habilitando así algunas como reclamos justos, y rechazando otras, consideradas como acciones de politización intolerable. ${ }^{38}$ Estas imposiciones -sumadas a otras, provenientes de diversas agencias estatales y también de los ámbitos académicos- remiten, por un lado, al concepto de "indio hiperreal" introducido por Alcida Ramos, en tanto implica "un modelo que moldea los intereses de los indígenas a la forma y las necesidades de la organización: la fabricación del Indio perfecto, cuyas virtudes, sufrimientos e incansable estoicismo le han otorgado el derecho a ser defendido por los profesionales de los derechos indígenas." ${ }^{39}$ Pero este modelo, que justifica el financiamiento, el personal dedicado a su defensa y el cumplimiento de los parámetros internacionales de respeto a la diversidad -frente a los cuales el Estado se muestra afín- tiene como contracara

élites intelectuales de los propios pueblos indígenas y sus simpatizantes entre otros sectores de la población." El fin de este discurso es conducir a "la denuncia de injusticias (incluso crímenes) históricas cometidas contra los pueblos indígenas (genocidios, despojos, servidumbre, discriminaciones) y al planteamiento de derechos específicos que se derivan de estas injusticias y de la calidad de indígenas ("primero en tiempo, primero en derecho"; "recuperación de derechos históricos")", fundamentando y legitimando "la demanda de derechos humanos específicos de los pueblos indígenas."

En STAVENHAGEN, Rodolfo, "Los derechos indígenas: algunos problemas conceptuales", en Expediente de la Academia Americana de Derechos Humanos, p. 132.

\section{BRIONES, Claudia. La alteridad... Op. Cit.}

39. RAMOS, Alcida Rita, "The Hyperreal Indian”, en Critique of Anthropology, 1994, V. XIV, No 2, p. 18.

94 una operación de segregación y de definición de límites entre los "indios permitidos" ${ }^{40}$ y los que no lo están. Esta categoría sociopolítica pone atención sobre el proyecto cultural del neoliberalismo en el que se insertan estos procesos ambiguos, donde una mayor importancia de las voces indígenas choca con "the frustating limits on their transformative aspirations". ${ }^{41} \mathrm{El}$ uso de "indio" tiene como intención sugerir la perpetuación, en el sistema global, de la subordinación que el término históricamente connota. A su vez, "permitido" denuncia justamente "how governments are using cultural rights to divide and domesticate indigenous movements", 42 en tanto "reforms have pre-determined limits; benefits to a few indigenous actors are predicated on the exclusion of the rest; certain rights are to be enjoyed on the implicit condition that others will not be raised". ${ }^{4}$

Los requisitos de reconocimiento ordenados en los proyectos y programas estatales son parte activa de estas operaciones de segregación y modelización. Esto permite problematizar el teórico respeto igualitario al derecho de autoadscripción, que sólo se sostiene discursivamente como una mera "retórica polí-

40. Categoría inicialmente acuñada por Silvia Rivera Cusicanqui y retomada y desarrollada en Hale, C., "Rethinking Indigenous Politics in the Era of the 'Indio Permitido"', 2004, en NACLA Report on the Americas, V. XXVIII, No 2.

41. "Limites frustrante a sus aspiraciones transformadoras”, en Hale, C. “Rethinking...”, Op. Cit., p. 17.

42. "los gobiernos están utilizando los derechos culturales para dividir y domesticar a los movimientos indígenas", en Hale, C. “Rethinking...”, Op. Cit., p. 17.

43. "las reformas tienen limites preestablecidos; beneficios para unos pocos actores indígenas que se basan en la exclusión de los demás, ciertos derechos se gozan de la condición implicita de que no se plantearon otros", en Hale, C. "Rethinking...", Op. Cit., p. 18. 
ticamente correcta del Estado”. ${ }^{44}$ Por último, permite también poner en cuestión el discurso inclusivo y pluricultural, ya que como indica Hale, "it would be a mistake to equate the increasing indigenous presence in the corridors of power with indigenous empowerment" ${ }^{45}$

\section{El Estado y la legitimación de lo ilegitimo}

Luego de lo planteado, podemos considerar que el Estado se materializa a sí mismo, a su entramado ideológico y a su propia lógica, a través de las diversas prácticas que performan $\mathrm{y}$ alinean el accionar de los Pueblos originarios según su propio concepto de otredad étnica. El "Estado realmente nunca deja de hablar", ${ }^{46}$ es decir, se expresa en múltiples formas, más o menos sutiles, pero todas fortalecedoras de su cualidad "omnipresente", autolegitimadoras de sus lógicas y naturalizadoras de su imposición y de la desigualdad implícita en la relación con él. En los casos analizados, una agencia específica del Estado impone modos de actuar y proceder muchas veces opuestos al discurso de la inclusión y el respeto a la diversidad étnica y cultural. En este sentido, coincidimos con que

para aprehender la materialidad del Esta44. GOROSITO KRAMER, Ana María. "Convenios y leyes: la retórica políticamente correcta del Estado”, en Cuadernos de Antropología Social, Buenos Aires, 2008, No 28.

45. "seria un error equiparar la creciente presencia indigena en los pasillos del poder con el empoderamiento indígena", en Hale, C. "Rethinking...”, Op. Cit., p. 17.

46. CORRIGAN, Philipe y SAYER, Derek. "El gran arco: la formación del estado inglés como revolución cultural", en Lagos, María y Calla, Pamela (compiladores) Antropología del Estado. Dominación y prácticas contestatarias en América Latina, Bolivia, 2008. Cuaderno de Futuro No 23. Informe sobre desarrollo humano, pp.1-47. do es necesario examinar lo que se esconde detrás de su propio discurso porque ... el éxito del poder del Estado radica en que éste esconde la historia y las relaciones de opresión detrás de una máscara ahistórica de ilusiones legitimantes... el Estado no es la realidad que está detrás de la máscara de prácticas políticas sino que es la máscara misma. $^{47}$

En este caso, la contradicción entre lo enunciado y las prácticas invita a problematizar la aparente "doble lógica de visibilización e invisibilización" operada sobre las demandas indígenas. No creemos que esta ambigüedad constituya un efecto no deseado, por la distancia ente las esferas de legislación y aplicación de la norma, sino un mecanismo funcional de normalización que el Estado impone sobre los sujetos políticos y sus luchas. En este sentido,

si bien se comprende que toda legislación tenderá a la homogeneización por el simple hecho de aplicar criterios que son generales, ésta no debería ser limitante en el segundo aspecto; pero por fuera de esos marcos de regulación y homogeneización con que el Estado formatea las luchas políticas, no está garantizado el acceso a los derechos. ${ }^{48}$

Así, la planificación y ejecución del RENACI, RETECI y RENOPI constituyen los modos concretos en los que se expresan estos marcos de regulación y el análisis de sus procedimientos evidencia que el Estado no puede escapar del uso de la violencia como medio para lograr ese fin. Sin embargo, este uso se oculta bajo un discurso inclusivo, cuyo rasgo a

47. Ídem., p.52.

48. TOLOSA, Sandra, "Relaciones constitutivas: indígenas y estructuras de poder del estado. El caso de la Comunidad India de Quilmes", en Revista Colombiana de Antropología. (En prensa). 
destacar es que "al autopresentarse como "posibilitador" hace no sólo que sea aceptado, sino que sea percibido en muchos casos como un logro o un reconocimiento genuino". ${ }^{49}$ Así se opera una "legitimación de lo ilegítimo", sostenida a su vez por organizaciones, instituciones, intelectuales y técnicos, que directa o indirectamente contribuyen a la reproducción de las prácticas de legibilidad estatales.$^{50}$ En esta línea el Estado, al tener el poder de "nombrar", debe generar ese efecto de legibilidad a partir de "la producción tanto de un lenguaje como de un saber para el gobierno y herramientas empíricas que clasifiquen y regulen colectividades" 51 y para ello involucra a actores profesionales y científicos que avalen esa construcción. Creemos necesario que, desde las disciplinas afectadas, se realice un análisis minucioso de las implicancias de la participación en este tipo de proyectos, considerando sus aspectos positivos y negativos y teniendo en cuenta sus implicancias en el control político de las comunidades.

Por supuesto los Pueblos originarios y sus comunidades adoptan estratégicamente "el lenguaje de la dominación para ser escuchados", dada la posibilidad de ser incluidos en el diálogo luego de centurias de silenciamiento. Sin embargo, es necesario definir los límites de la estrategia y reconocer peligros laterales. ¿Qué implicancias puede traer aparejadas la aceptación de este tipo de inclusión con sus categorías, formularios, programas y tiempos

\section{9. Ídem., p. 9.}

50. SCOTT, James, Seeing Like a State: How Certain Schemes to Improve the Human Condition Have Failed, CT: Yale University Press, New Haven, 1998.

51. TROUILLOT, Michel-Rolph. "The Anthropology of the State in the Age of Globalization: Close Encounters of the Deceptive Kind", 2001, en Current Anthropology, V. XLII, No 1, pp. 125-138.

96 propios? ¿Cuál es el límite entre oportunidad y peligro que conlleva el discurso actual sobre un "contexto histórico e importante como nunca se había dado en 200 años", o sobre las actuales políticas públicas indígenas, que pese a sus falencias, "son un gran avance y deben ser aplicadas, porque dan cuenta de este nuevo contexto"? ?2

Como ya mencionáramos, uno de los peligros más evidentes del discurso estatal sobre su propia política es la utilización del argumento inclusivo y de la participación, que genera en muchos indígenas una percepción positiva sobre los logros alcanzados, que en muchos casos se perciben como genuinos. Si bien nuestra mirada sobre este punto es crítica, no podemos dejar de evaluar sin embargo, que surgen ciertos efectos positivos de estos mecanismos: por ejemplo la enfatización de los procesos de toma de conciencia étnica en muchas comunidades, antes inexistentes. La misma búsqueda de datos para responder lo requerido por los registros ha sido fértil para la recuperación de información sobre aspectos culturales, familiares, políticos, históricos, arqueológicos, etc., Estos procesos han propiciado a su vez nuevos movimientos de organización comunal.

También, y como contrapartida, se han generado por oposición, lógicas de acción, agentividad y resistencia frente al Estado, así como críticas hacia muchos de sus mecanismos, propuestas de cambio y reclamos de respuestas más plurales. En este sentido, los sujetos y organizaciones abyectados de los límites de aceptación estatal, son también parte activa del mismo, ya que lo confrontan generando una dinámica que puede producir transformacio-

52. Estos entrecomillados parafrasean a decires comunes que se reproducen en los circuitos cercanos al INAI. 
nes, en tanto parte de la misma disputa política. Siguiendo a Trouillot,

mientras que abundan los signos de la rutinización de la presencia gubernamental en las vidas de los ciudadanos de todas partes, este fin de siglo también nos brinda imágenes del poder gubernamental desafiado, desviado, o simplemente dando lugar a instituciones infra o supranacionales. ${ }^{53}$

\section{Palabras Finales}

La existencia de un límite de inclusión y un exterior constitutivo que resiste las imposiciones, indica que las prácticas estatales y sus formas intrínsecas de violencia epistémica e institucional constituyen también actos de violencia simbólica, en cuanto a las representaciones e imaginarios que producen, reproducen y legitiman. Sin embargo, este aspecto simbólico, al ser resistido, se transforma y muestra su límite. Es allí donde el marco ideológico subyacente, expresado en las formas de violencia mencionadas, se transforma en argumento o justificación de prácticas represivas. Esto advierte sobre que, tras las formas conceptualizadas unilaterales sobre la indigenidad, y de los mecanismos institucionalizados que las regulan, existe el control estatal sobre el accionar político de los Pueblos. También, que la pretendida pluralidad se ve cuestionada si los mecanismos se imponen de manera vertical sin atender la diversidad real. Por último, que la normalización de la indigenidad deja por fuera un campo exterior donde las formas de organización y vida de los Pueblos que no desean participar de la lógica de negociación estatal, no son reconocidas como genuinas y

53. Ídem, p. 2. por lo tanto no pueden acceder a los derechos que deberían ser igualitarios. Esto contribuye a la reproducción de un discurso único y hegemónico sobre la indigenidad, que reproduce la deshistorización, invisibilización y homogeneización de los Pueblos originarios, en tanto los modeliza. En este sentido, creemos que un análisis profundo sobre los mecanismos institucionalizados y sus procedimientos -del cual aquí hemos sugerido los pasos inicialeses necesario para identificar, desnaturalizar y "desneutralizar" estas construcciones, con el fin de resistirlas y revertirlas. A su vez, eso puede contribuir a dilucidar ciertas ideas que, originadas en contextos particulares, fueron sedimentando en el sentido común y continúan operando como fundamento de prácticas sociales de marcación y diferenciación social, avaladas por el Estado y reproducidas por la población en general.

Por último, pero no menos importante, no podemos olvidar que las luchas indígenas por sus derechos se centran en la reivindicación sobre sus territorios ancestrales, expropiados por la colonia primero y luego por el Estado nación. Recordar este punto ayuda a no restringir el problema a aspectos simbólicos o categoriales, sino que se comprende que la lucha política tiene como meta la recuperación de los territorios y el manejo de los recursos existentes en ellos. A la luz de esto, ciertas lógicas de manipulación del Estado sobre las acciones políticas de los Pueblos y sus comunidades indican que existe un interés en disputa entre el Estado y los indígenas, que remite a los fundamentos mismos del Estado nación. En este sentido, debemos recordar que tanto la ley 26.160 como el programa de relevamiento territorial constituyen sólo soluciones provi- 
sorias que dilatan un conflicto que es de muy difícil solución: la devolución de los territorios usurpados a los Pueblos originarios.

$\infty \ddot{e} \infty$

Recibido: 03/05/2013

Aceptado: 18/10/2013 